\title{
Graphs for Determining the Power of Student's $t$-Test
}

\author{
Mary C. Croarkin
}

(January 9, 1962)

\begin{abstract}
This paper presents charts for determining the operating characteristics of Student's $t$-test. For a fixed level of significance $\alpha$, the charts give constant contours of the power $\beta$ depicting the number of observations plotted against a function of the difference in means. Both the one-sample and the two-sample (equal sample sizes) cases are treated for all combinations of

$$
\begin{aligned}
\alpha & =0.01,0.02,0.05,0.10,0.20 \text { and } \\
\beta & =0.10,0.50,0.90,0.95,0.99 \text { except } \\
(\alpha, \beta) & =(0.10,0.10),(0.10,0.20)
\end{aligned}
$$
\end{abstract}

The graphs were constructed for two-sided tests but within the given accuracy are equally applicable to one-sided tests.

\section{Introduction}

It is the purpose of this paper to provide charts for readily ascertaining the operating characteristics or power curve of Student's $t$-test. When a statistical test procedure is being selected, oftentimes the power of the test is not examined because of the difficulties in computing the power curve, or at best the power is computed at a single point. The charts given in this paper will provide four or five (depending on the level of significance) points on the power curve, and these points together with the level of significance should be sufficient for a graphical approximation of the power function.

Other tabulations of the noncentral $t$-distribution have been made by Neyman [3], ${ }^{1}$ Neyman and Tokarska [4], Resnikoff [5], Resnikoff and Lieberman [6], Johnson and Welch [2], and Davies (Tables E and E.1) [1].

The tables given in Davies [1] are by far the most convenient for evaluating the power of Student's t-test in routine applications; the charts presented here are essentially a graphical extension of these tables. All charts are the result of calculations done at the National Bureau of Standards in connection with a table of the noncentral $F$ distribution [7].

\section{One-Sample Case}

Assume $X_{1}, \ldots, X_{n}$ is a random sample of $n$ observations from a normal distribution with mean $\mu$ and variance $\sigma^{2}$ and that we are interested in testing the null hypothesis $H_{0}$ that $\mu=\mu_{0}$ against the alternate hypothesis $H_{1}$ that $\mu \neq \mu_{0}$. If $H_{0}$ is true, then the statistic ${ }^{2}$

$$
t=\frac{\sqrt{n}\left(\bar{X}-\mu_{0}\right)}{s_{x}}
$$

${ }^{1}$ Figures in brackets indicate the literature references at the end of this paper. $2 \bar{X}=\sum_{1}^{n} X_{i} / n, s_{x}=\sqrt{\Sigma\left(X_{i}-\bar{X}\right)^{2} /(n-1)}$. is known to follow Student's t-distribution with $(n-1)$ degrees of freedom; however, if $H_{1}$ is true, $t$ follows a noncentral $t$ distribution with $(n-1)$ degrees of freedom.

The usual test procedure is to choose the level of significance $\alpha$ from which a value $t_{\alpha}$ can be determined such that

$$
\operatorname{Pr}\left\{|t|>t_{\alpha} \mid H_{0} \text { true }\right\}=\alpha .
$$

Then the proper decision rule at the $\alpha$ level of significance is to

$$
\begin{aligned}
& \text { accept } H_{0} \text { if }|t| \leq t_{\alpha} \\
& \text { accept } H_{1} \text { if }|t|>t_{\alpha} .
\end{aligned}
$$

When the alternate hypothesis $H_{1}$ is true, i.e., when $\mu \neq \mu_{0}$, then the probability of accepting $H_{1}$ is termed the power of the test and is given by

$$
\beta=\operatorname{Pr}\left\{|t|>t_{\alpha} \mid H_{1} \text { true }\right\}=\operatorname{Pr}\left\{\text { accept } H_{1} \mid H_{1} \text { true }\right\} .
$$

\section{Two-Sample Case}

Suppose we are given two random samples from normal populations, say, $X_{1}, \ldots, X_{n}$ and $Y_{1}, \ldots$, $Y_{n}$ with means $\mu_{1}$ and $\mu_{2}$ respectively and unknown variances $\sigma^{2}$. Then the problem of testing the null hypothesis $H_{0}$ that $\mu_{1}=\mu_{2}$ against the alternate hypothesis $H_{1}$ that $\mu_{1} \neq \mu_{2}$ is resolved by considering the $t$-statistic ${ }^{3}$

$$
t=\frac{\sqrt{n}(\bar{X}-\bar{Y})}{\sqrt{s_{x}^{2}+s_{y}^{2}}}
$$

with $2(n-1)$ degrees of freedom and applying the test procedure indicated by (3).

$$
{ }^{3} \bar{Y}=\sum_{1}^{n} Y_{i} / n, s_{y}=\sqrt{\Sigma\left(Y_{i}-\bar{Y}\right) /(n-1)} .
$$




\section{Use of Charts}

The power of Student's $t$-test depends upon three parameters: $\Delta$, the difference between means where $\Delta=\left|\mu-\mu_{0}\right|$ for the one-sample case, and $\Delta=\left|\mu_{1}-\mu_{2}\right|$ for the two-sample case; the number of observations; and the level of significance. The charts given in this paper depict a standardized difference $\delta=\Delta / \sigma$ plotted against $n$ for fixed $\alpha$ and $\beta$. Figures 1-5 deal with the one-sample case; whereas figures $6-10$ deal with the two-sample case. It should be noted that on all graphs dealing with the two-sample case, $n$ is the number of observations in each sample.

$$
\alpha=\left\{\begin{array}{l}
\text {.OI FOR TWO }- \text { SIDED TEST } \\
\text {.OO5 FOR ONE - SIDED TEST }
\end{array}\right.
$$

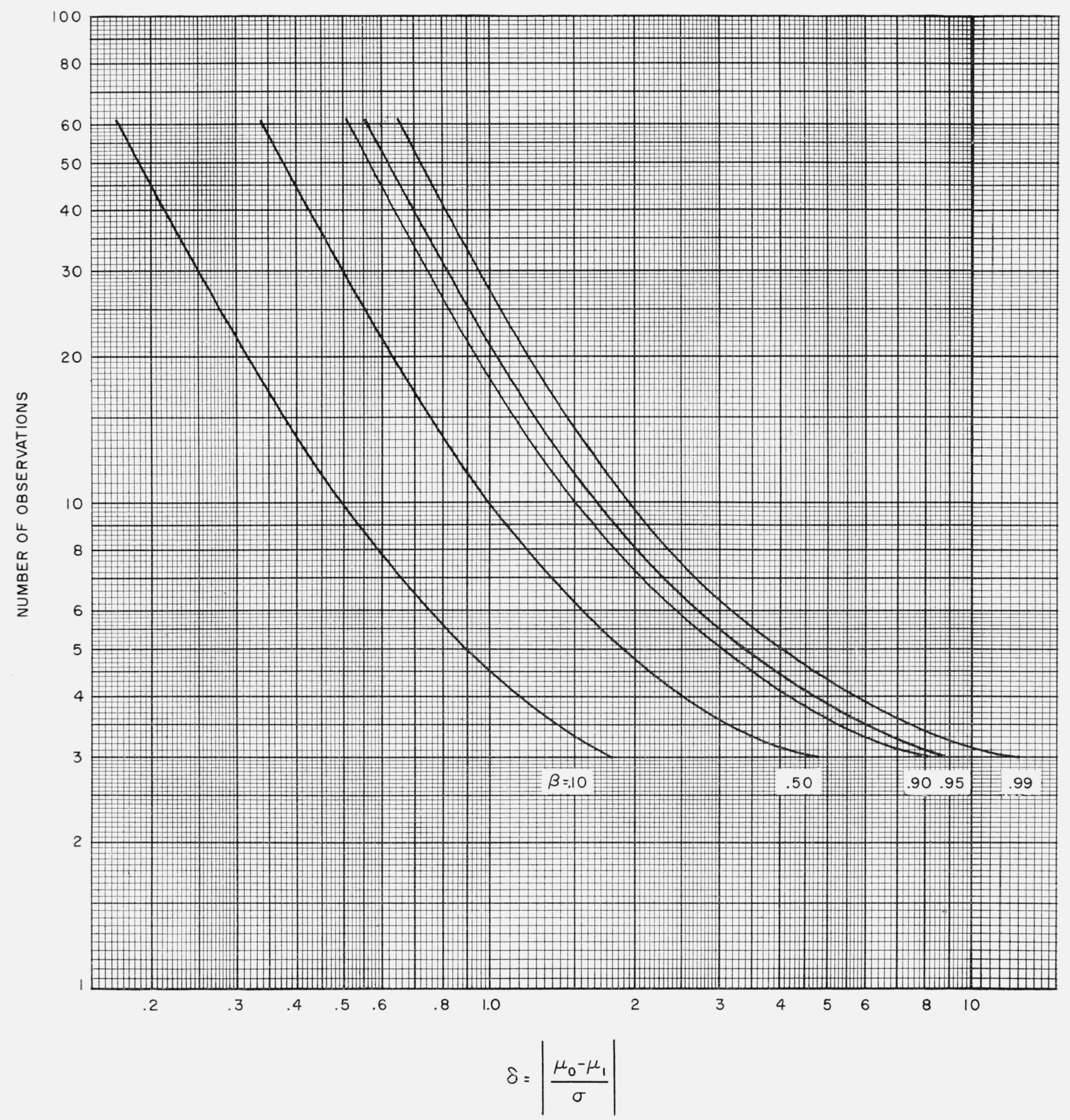

Figure 1. Curves of constant power $(\beta)$ for t-test of mean. 
All charts were constructed for a two-sided or symmetrical $t$-test at level of significance $\alpha$. However, within the accuracy of these charts, the onesided test will be equivalent to the two-sided test, and hence these same graphs can be used for an asymmetrical $t$-test where the appropriate level of significance will now be $\alpha / 2$ instead of $\alpha$.

\section{Applications}

Example 1. Suppose that we plan to take $n=10$ observations and carry out a two-sided $t$-test for the population mean at level of significance $\alpha=0.05$ and that we are interested in the power curve of such a test.

\section{$\alpha=\left\{\begin{array}{l}.02 \text { FOR TWO-SIDED TEST } \\ .01 \text { FOR ONE - SIDED TEST }\end{array}\right.$}

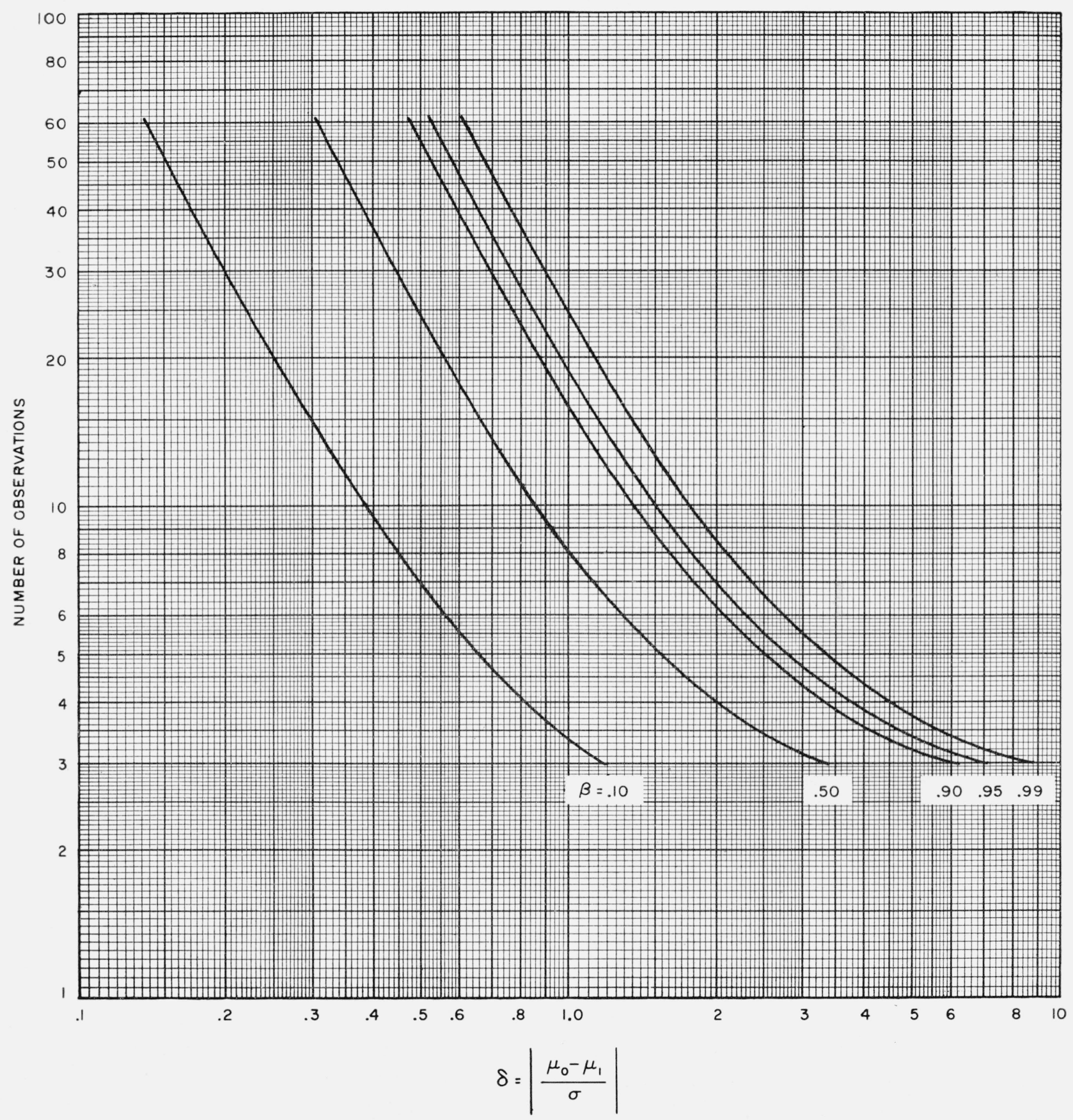

Figure 2. Curves of constant power ( $\beta$ ) for t-test of mean. 


\section{$\alpha=\left\{\begin{array}{l}.05 \text { FOR TWO-SIDED TEST } \\ .025 \text { FOR ONE-SIDED TEST }\end{array}\right.$}

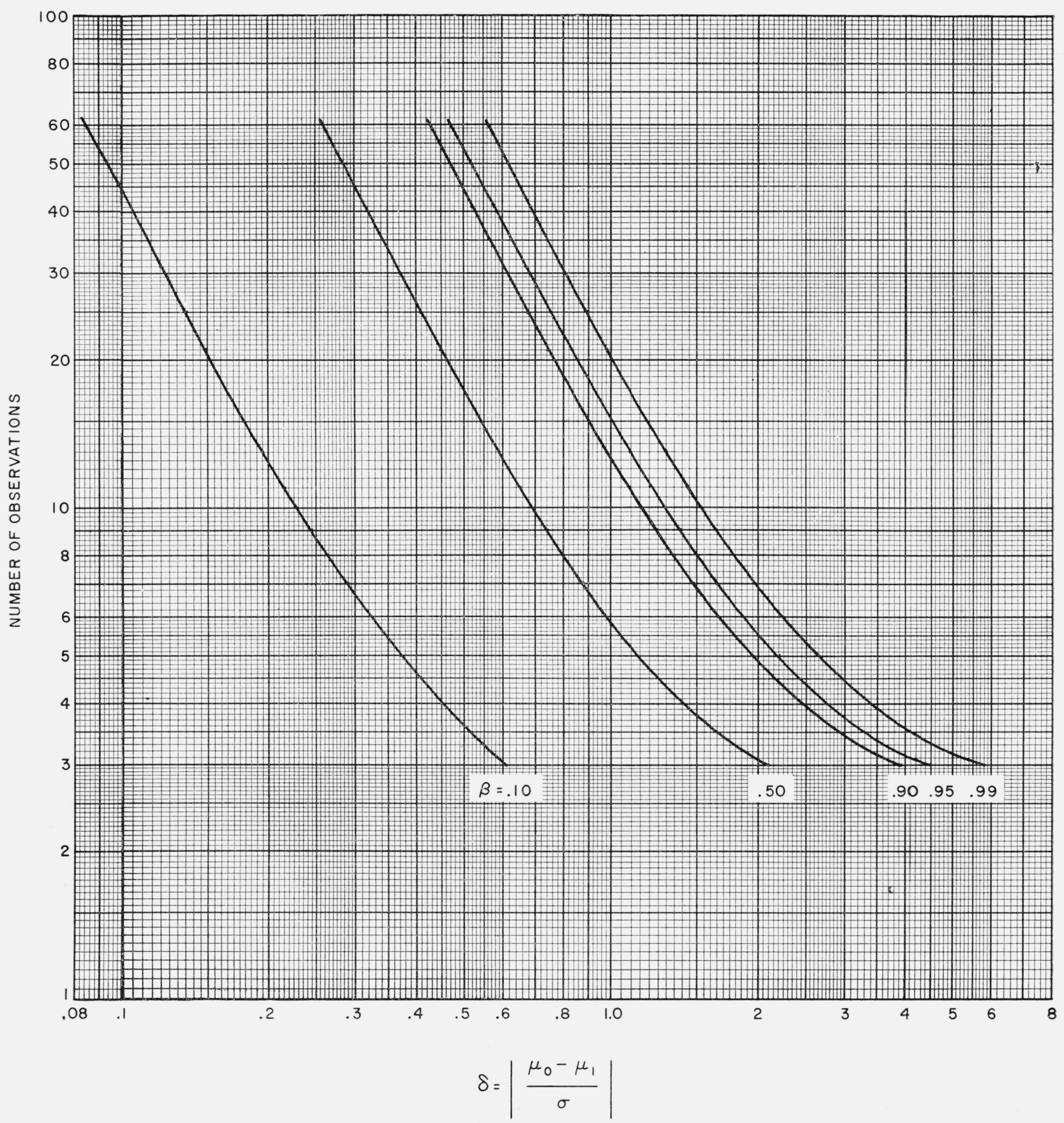

Figure 3. Curves of constant power ( $\beta$ ) for t-test of mean

Locating the horizontal line at $n=10$ on figure $3, \mid$ ability $\beta=0.10,0.50,0.90,0.95$, and 0.99 . These we can read off the inve values of the standardized difference $\delta=\frac{\mu-\mu_{0} \mid}{\sigma}$ which can be detected with probfive points, which are tabulated below, together with the level of significance $\alpha=0.05$ are sufficient to graph the power curve of that particular test. A sketch of this graph is given in figure 11 . 


$$
\alpha=\left\{\begin{array}{l}
\text { IO FOR TWO-SIDED TEST } \\
.05 \text { FOR ONE - SIDED TEST }
\end{array}\right.
$$

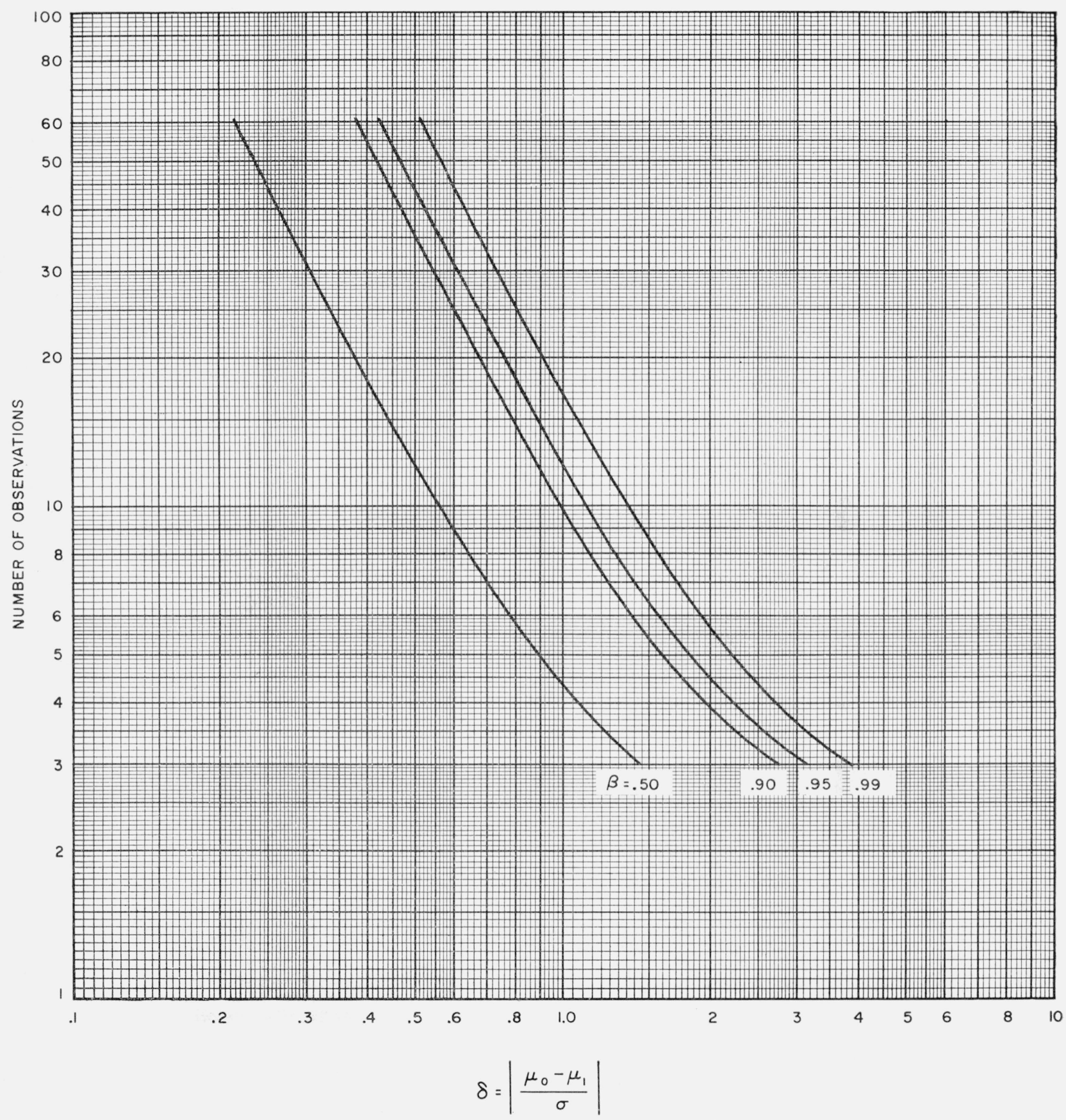

Figure 4. Curves of constant power $(\beta)$ for t-test of mean.

\begin{tabular}{|c|c|}
\hline Power $(\boldsymbol{\beta})$ & $\frac{\mu-\mu_{0}}{\sigma}$ \\
\hline $\begin{array}{r}0.10 \\
.50 \\
.90 \\
.95 \\
.99\end{array}$ & $\begin{array}{r}0.23 \\
.69 \\
1.15 \\
1.30 \\
1.52\end{array}$ \\
\hline
\end{tabular}

The entire power curve enables one to find the corresponding power $\beta$ for any standardized difference $\delta$. For example, the probability of detecting a difference of one standard deviation, $\delta=1.0$, would be found from the graph to be 0.76 . 


\section{$\alpha=\left\{\begin{array}{l}.20 \text { FOR TWO }- \text { SIDED TEST } \\ .10 \text { FOR ONE }- \text { SIDED TEST }\end{array}\right.$}

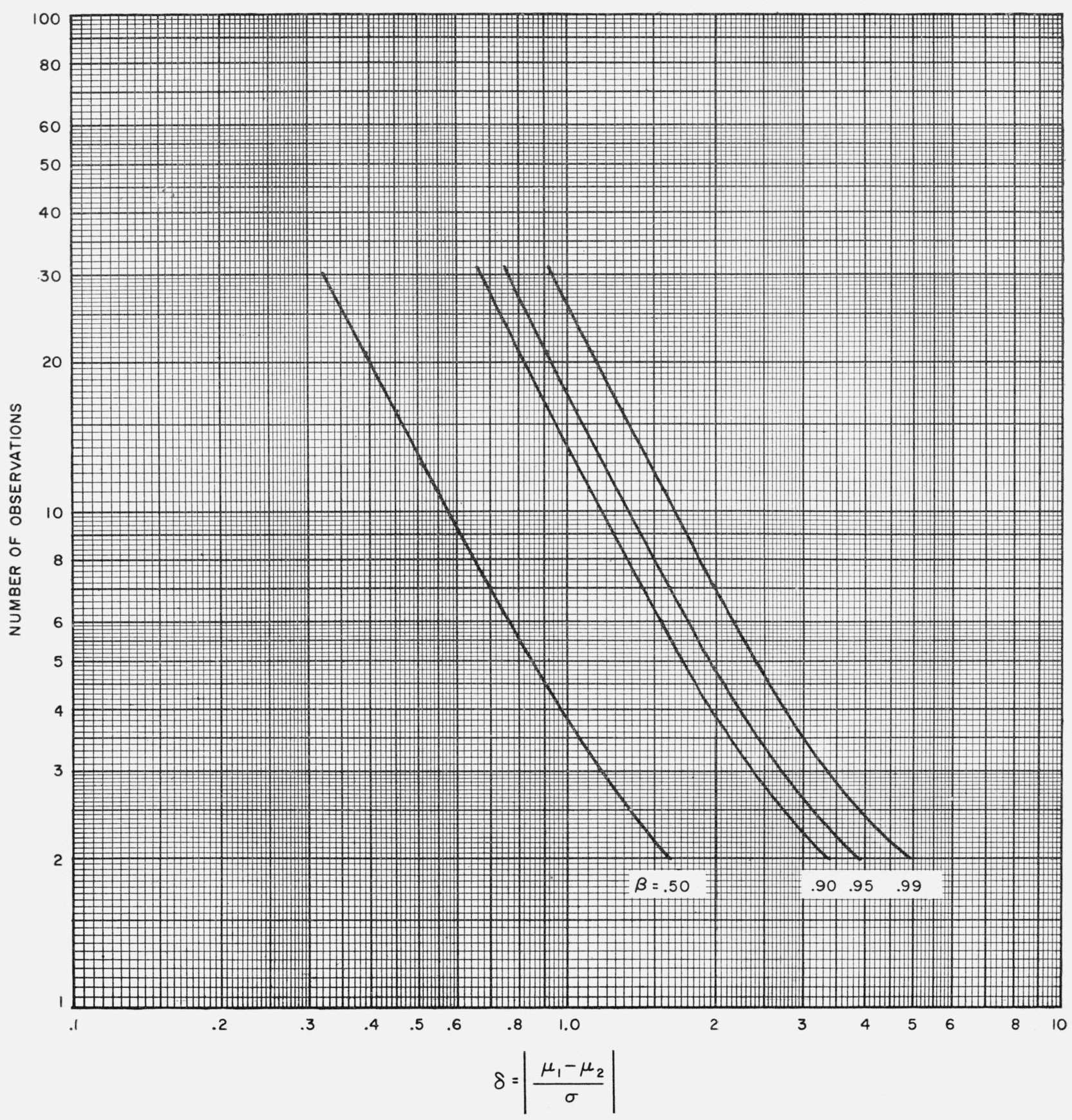

Figure 5. Curves of constant power ( $\beta$ ) for t-test of mean.

Example 2. How many observations are necessary to detect a difference of at least $2 \sigma$ between the means of two normal populations with a probability of $\beta=0.95$ using a two-sided $t$-test at level of significance $\alpha=0.10$ ?
Using figure 9 we see that the $\delta=2$ line intersects the $\beta=0.95$ curve at approximately 6.2 . Therefore, seven observations from each population would be necessary to detect a difference of $2 \sigma$ between the population means. 


$$
\alpha=\left\{\begin{array}{l}
.01 \text { FOR TWO-SIDED TEST } \\
.005 \text { FOR ONE-SIDED TEST }
\end{array}\right.
$$

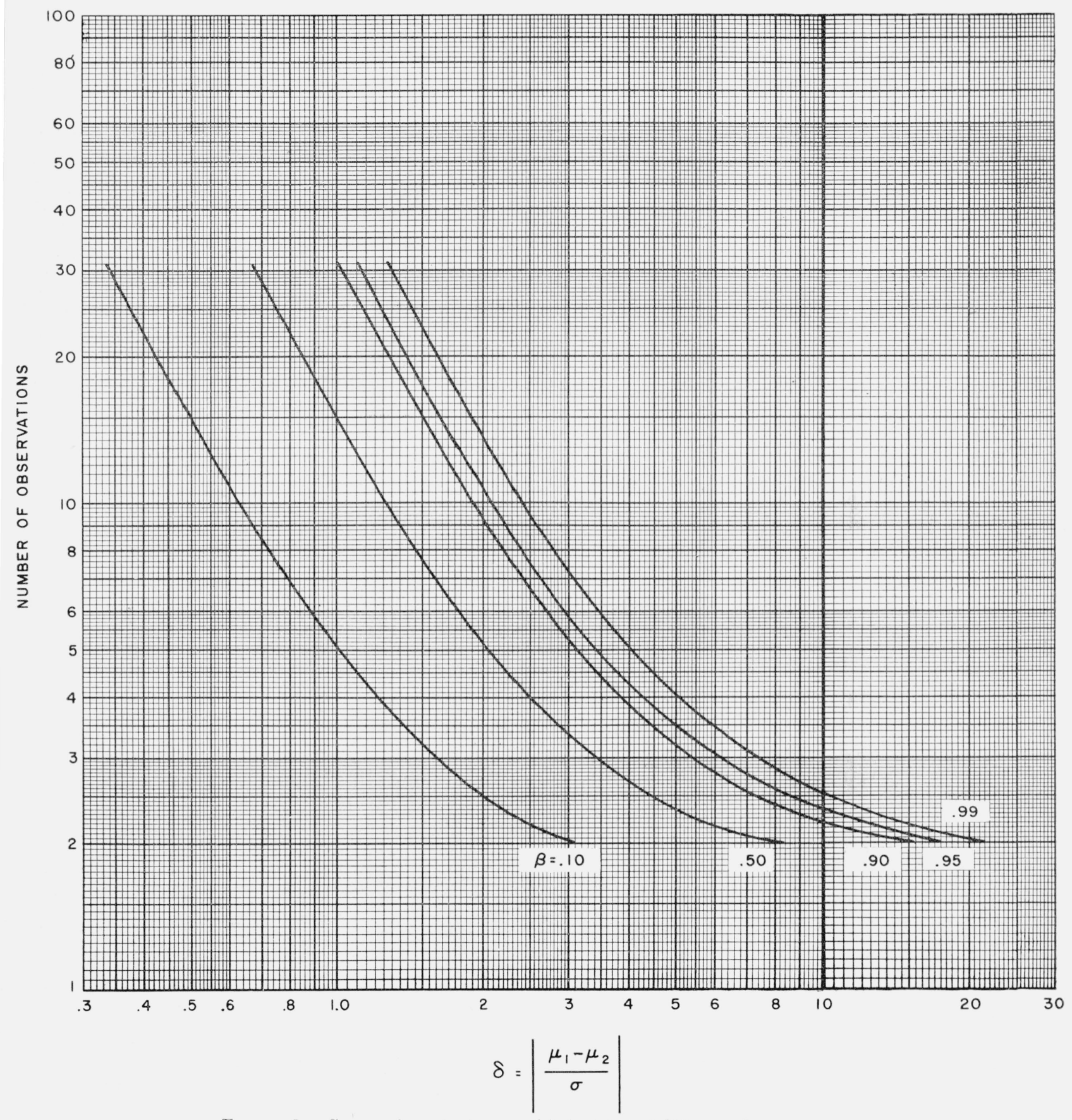

FiguRe 6. Curves of constant power ( $\beta$ ) for t-test of difference between means.

Example 3. It is planned to carry out a one-sided $t$-test for comparing two population means at level of significance $\alpha=0.01$. The problem is to find the power curve when $n=5$ observations are taken from each population.

From figure 7 we see that the values of the standardized difference $\delta$ corresponding to $\beta=0.10,0.50$, $0.90,0.95,0.99$ for $n=5$ are: (see fig. 12 )

\begin{tabular}{c|c}
\hline \hline Power $(\boldsymbol{\beta})$ & $\delta=\left|\frac{\mu_{1}-\mu_{2}}{\sigma}\right|$ \\
\hline 0.10 & 0.78 \\
.50 & 1.77 \\
.90 & 2.78 \\
.95 & 3.08 \\
.99 & 3.60
\end{tabular}




$$
\alpha=\left\{\begin{array}{l}
.02 \text { FOR TWO-SIDED TEST } \\
.01 \text { FOR ONE-SIDED TEST }
\end{array}\right.
$$

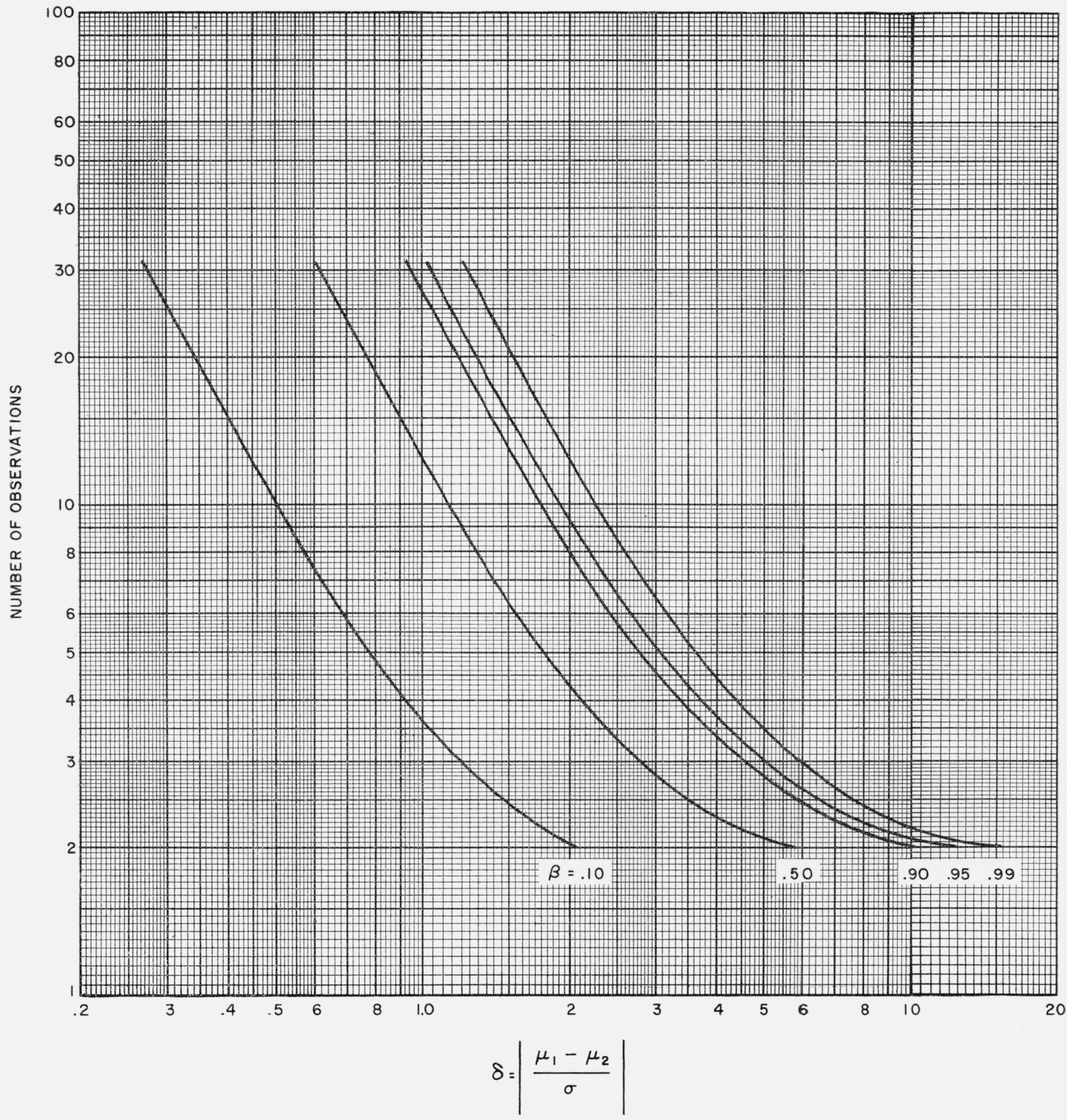

Figure 7. Curves of constant power ( $\beta$ ) for t-test of difference between means. 


$$
\alpha=\left\{\begin{array}{l}
.05 \text { FOR TWO -SIDED TEST } \\
.025 \text { FOR ONE - SIDED TEST }
\end{array}\right.
$$

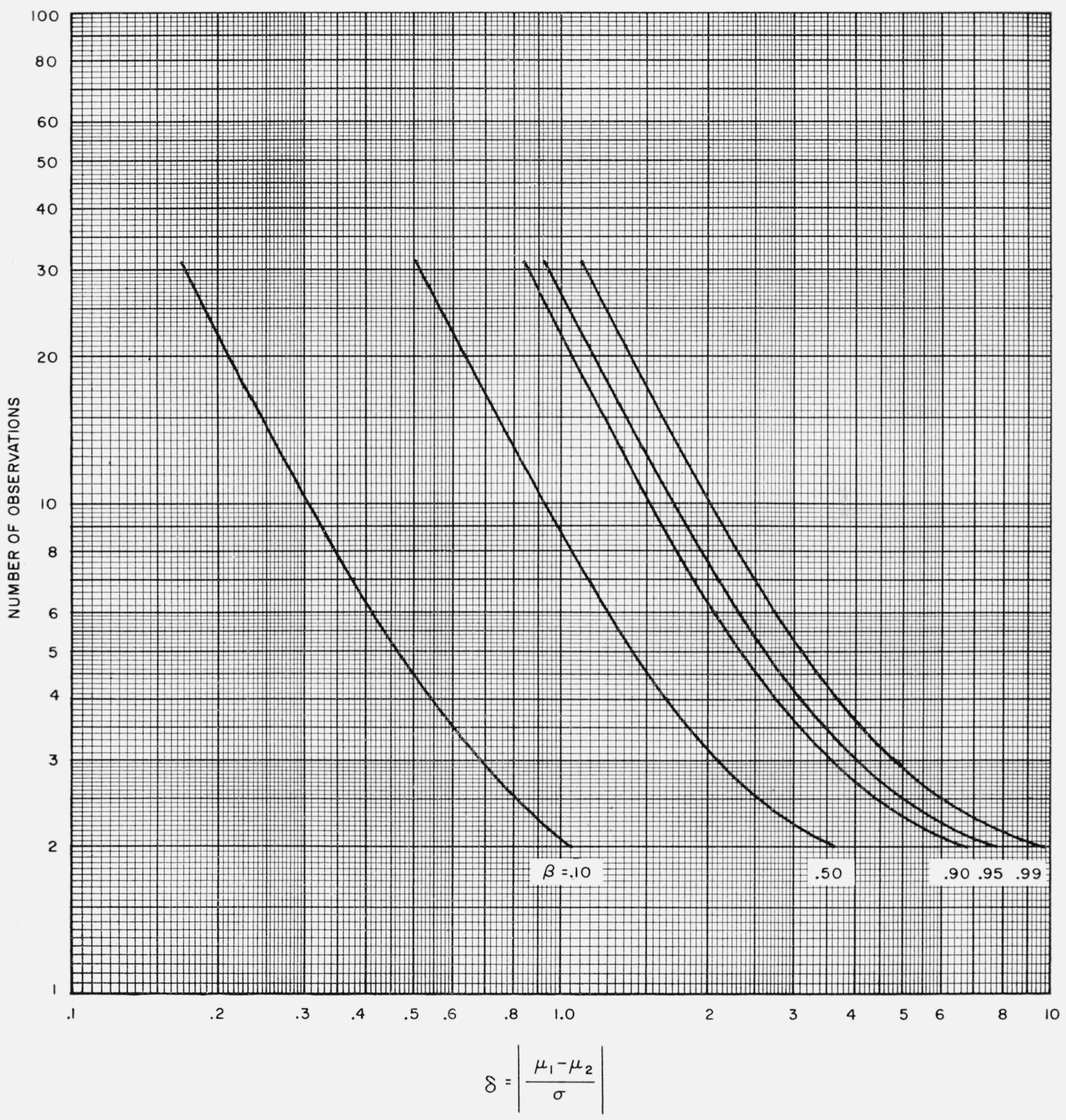

Figure 8. Curves of constant power ( $\beta$ ) for t-test of difference between means. 


$$
\alpha=\left\{\begin{array}{l}
.10 \text { FOR TWO-SIDED TEST } \\
.05 \text { FOR ONE-SIDED TEST }
\end{array}\right.
$$

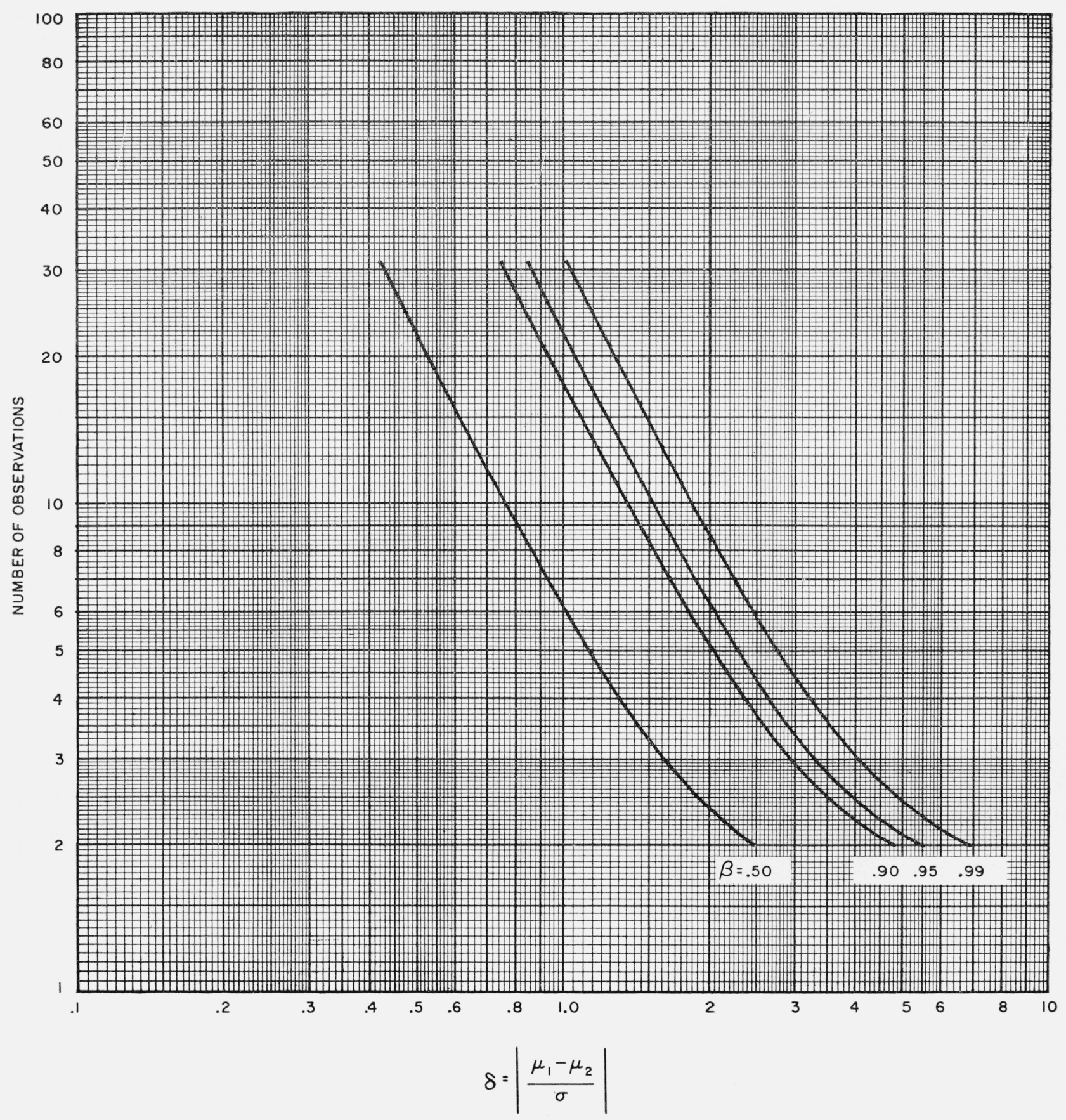

FIGURE 9. Curves of constant power ( $\beta$ ) for t-test of difference between means. 


$$
\alpha=\left\{\begin{array}{l}
20 \text { FOR TWO-SIDED TEST } \\
10 \text { FOR ONE - SIDED TEST }
\end{array}\right.
$$

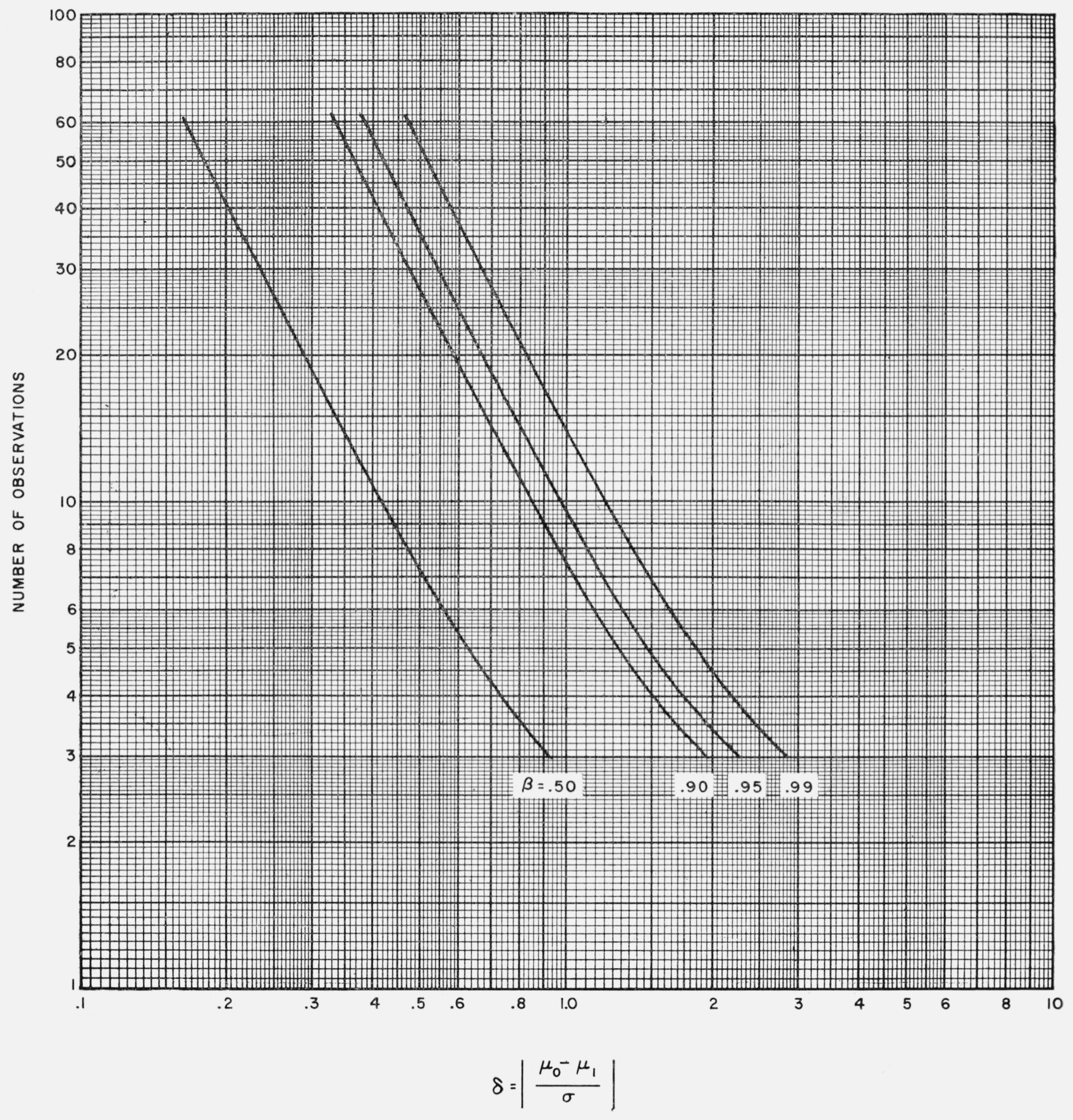

Figure 10. Curves of constant power ( $\beta$ ) for t-test of difference between means. 


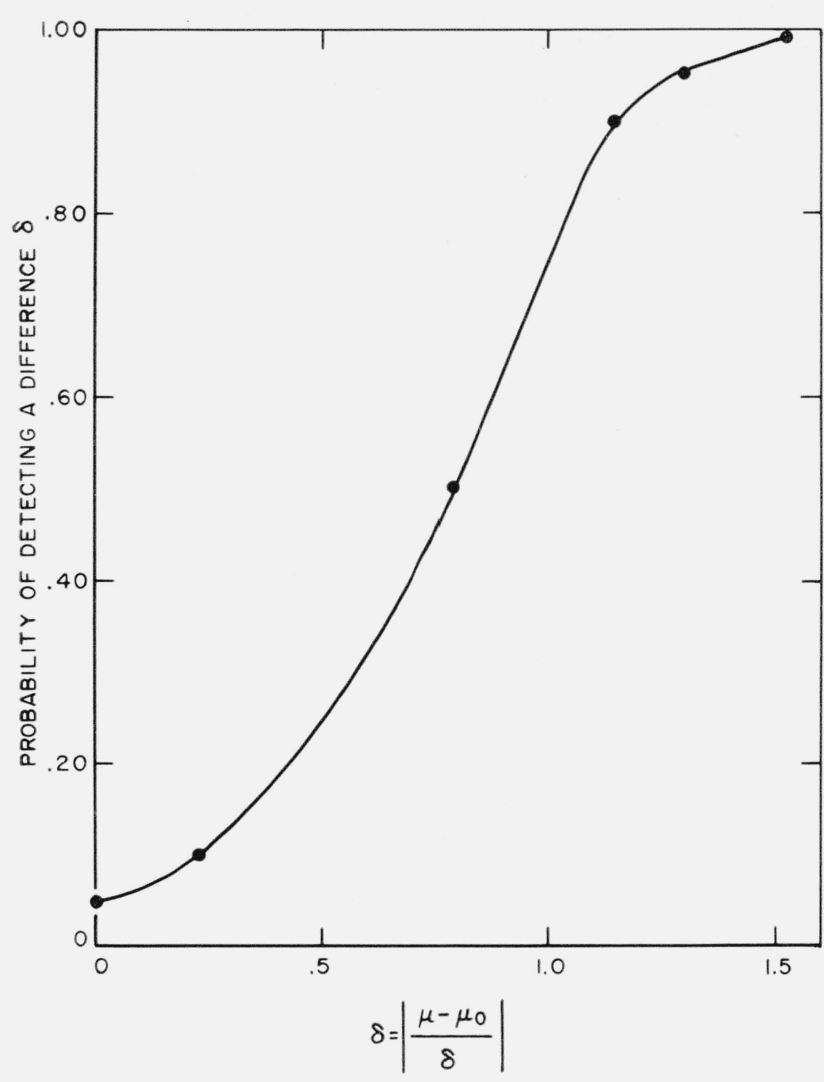

Figure 11. Power curve for a two-sided t-test of the population mean where $\mathrm{n}=10$ and $\alpha=0.05$.

The author thanks Marvin Zelen for innumerable contributions to this paper.

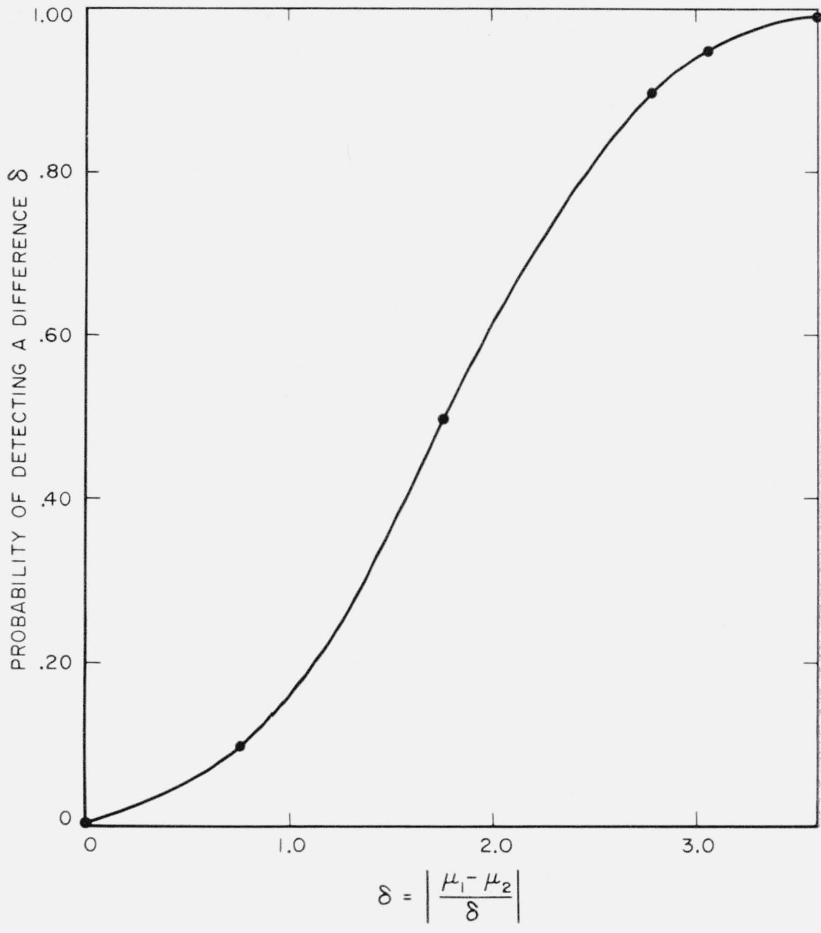

Figure 12. Power curve for a one-sided t-test for comparing the means of two populations where $\mathrm{n}=5$ and $\alpha=0.01$.

\section{References}

[1] Davies, Owen L., The Design and Analysis of Industrial Experiments, Hafner Publ. Co., New York, 1954.

[2] Johnson, N. L, and Welch, B. L., Applications of the non-central $t$-distribution, Biometrika 31, 362-389 (1940).

[3] Neyman, J., Statistical problems in agricultural experimentation, Supplement to the J. Roy. Statistical Soc. 2, 107-154 (1935).

[4] Neyman, J. and Tokarska, B., Errors of the second kind in testing "Student's" hypothesis, JASA 31, 318-326 (1936).

[5] Resnikoff, G. J., Tables to facilitate the computation of percentage points of the non-central $t$-distribution, Tech. Rept. No. 55, Stanford Univ. Press, Stanford, Calif., 1961.

[6] Resnikoff, G. J. and Lieberman, G. J., Tables of the noncentral $t$-distribution, Tech. Rept. No. 32, Stanford Univ. Press, Stanford, Calif., 1957.

[7] Tables of the non-central $F$ distribution, to be published by the National Bureau of Standards as part of its Applied Mathematics Series. 


\section{Publications of the National Bureau of Standards}

\section{Selected Abstracts}

Systems of electrical units, F. B. Silsbee, $J$. Research NBS 66C (Engr. and Instr.) No. 2 (Apr.-June 1962) 75 cents. The various systems of measurement, with their respective sets of units, used in the literature on electricity and magnetism are described in detail. Their historical development is summarized. The manner in which each is derived from either of the two alternative points of view of the experimentalist and the theoretician is compared and contrasted. The desirability of recognizing both points of view in international standardization, particularly when discussing rationalization, is pointed out. The present status of the absolute measurements on which all electrical units are based is reported, and tables are included for the conversion of equations and numerical values from one system to another.

Some problems connected with Rayleigh distributions, M. M. Siddiqui, J. Research NBS 66D (Radio Prop.) No. 2 (Mar.A pr. 1962) \%o cents.

This is an expository paper presenting the following: (1) the origin, and (2) the properties of the Rayleigh distribution; (3) the most efficient estimators of its parameters; (4) a test of the hypothesis that a set of observations is from a Rayleigh distribution; (5) the distribution of the ratio of two independent Rayleigh variates; and (6) the Rayleigh process derived from a normal process.

Impedance of a monopole antenna with a radial-wire ground system on an imperfectly conducting half space, Part I., S. W. Maley and R. J. King, J. Research NBS 66D (Radio Prop.) No.2 (Mar.-Apr. 1962) 70 cents.

The effectiveness of a radial wire ground system as an approximation to a radial conducting disk ground system for a vertical monopole antenna over an imperfectly conducting ground is investigated experimentally by means of impedance measurements. The results were compared with theoretical work by J. R. Wait. The comparison shows that Wait's formula for the effective surface impedance of a radial wire ground system gives results which agree well with the measurements.

Theory of the infinite cylindrical antenna including the feedpoint singularity in antenna current, R. H. Duncan, $J$. Research NBS 66D (Radio Prop.) No. 2 (Apr.-Mar. 1962) 70 cents.

The usual idealized model for a cylindrical antenna consists of an extremely thin walled tube of infinite conductivity with an infinitesimally narrow circumferential gap. Physically, one expects the antenna current at the feedpoint of such a model to be infinite. However, the singularity in feedpoint current is not detected by either iterative or Fourier series solutions of the integral equation for antenna current. These solutions are continuous on $z h$, where $h$ is the half-length of the antenna. They are also in good agreement with each other and with experimental data. From a formal point of view this amounts to saying that the conventional solutions of the integral equation are solutions on most, but not all, of the range $z h$. Inside a small region, $z z_{s}$, the correct solution to the integral equation is peculiar to the idealized generator. Low order iterative and Fourier series solutions ignore these peculiarities and produce a smooth current distribution which can be used in predicting the behavior of practical structures. This paper is concerned with a detailed study of the theoretical current near the feedpoint of the idealized model and the development of a definition of $z_{s}$.
The electric field at the ground plane near a disk-loaded monopole, J. Hansen and R. Larsen, J. Research NBS 66D (Radio Prop.) No. 2 (Mar.-Apr. 1962) 70 cents.

In calculating ground losses for antennas with a ground wire system it is necessary to know the vertical electric field strength and the tangential magnetic field strength at the surface of the ground.

In this paper the vertical electric field strength at the ground plane near the base of an electrically short vertical antenna with a top loading in the shape of a circular disk is calculated. Numerical computations are carried out to some extent.

Propagation of plane electromagnetic waves past a shoreline, J. Bazer and S. N. Karp, J. Research NBS 66D (Radio Prop.) No. 3 (May-June 1962) 70 cents.

The problems of the diffraction of homogeneous plane waves and ground waves by a linear shoreline in a planar land-sea surface are discussed. The direction of propagation of these incident waves is assumed perpendicular, and that of their magnetic vectors parallel, to the shoreline. At the air-land interface, the customary impedance boundary condition is imposed while the sea is treated as a perfect conductor; atmospheric and ionospheric effects are ignored. Exact integral representations of the solutions are presented. In the case of homogeneous plane-wave excitation originating over the sea, the integral representations are employed to obtain expressions for the geometrical optics field and for the farfield form of the remaining scattered field, transition regions included. The possibility of coastal refraction is discussed.

Currents induced on the surface of a conducting circular cylinder by a slot, G. Hasserjian and A. Ishimaru, J. Research NBS 66D (Radio Prop.) No. 3 (May-June 1962) 70 cents.

This paper is a partial study of currents induced on circular, conducting cylinders by narrow radiating slots. First, a brief and general formulation of the radiation fields of slots on cylinders is made. Then, the problem of an infinite axial slot is examined thoroughly for all cylinder sizes. An expansion for the fields, very close to the slot, on large radius cylinders, is also obtained. Sample computations are made, for various ranges of cylinder radius, and the order of the errors is discussed.

The problem of a circumferential slot, of constant excitation, is also considered. An asymptotic expansion obtained for this case yields the surface current distribution for values of axial distances that are smaller than the square of the circumference of the cylinder.

Since one of the objectives of this study is to determine mutual coupling between two slots on a cylinder, the last section presents a formulation of the equivalent network in terms of the surface and feed line currents.

Periodicity modulo $m$ and diversibility properties of the partition function, M. Newman, Trans. Am. Math. Soc. 97, No. 2, 225-236 (Nov. 1960).

It is proved that modulo 2, 5, 13 the unrestricted partition function $p(n)$ fills all residue classes infinitely often, and similar theorems for related functions are proved.

Applications of statistics in Post Office automation, B. M. Levin and N. C. Severo, Am. Statistician 15, No. 4, 14-18 (Oct. 1961).

The National Bureau of Standards is involved in designing and developing equipments and systems for the improved sorting of mail. As part of this project numerous statistical studies - mostly of a sampling type - have been conducted. 
These studies were designed to obtain research and development information which is not collected by the Post Office as part of its routine data collecting activities. The data from these studies have proved useful as a basis for making administrative decisions, for developing efficient mechanized schemes of sorting mail, and for costing these schemes. This paper presents a thumbnail sketch of the Post Office mechanization problem, a description of the statistical problems encountered with some results of corresponding studies, and some of the uses to which the data have been put. $\ldots$

What is the best value? W. J. Youden, J. Wash. Acad. Sci 51, No. 6, 95-97 (Oct. 1961).

Investigators measuring physical constants frequently try various combinations of apparatus components and vary the operating conditions. Ideally none of these changes should affect the outcome. In fact very small effects are usually associated with many such alterations in the measurement procedure. A simple average of the various measurements may give undue weight to one or another of the substitutions when no basis exists for favoring one over the other. This note indicates how a planned program of changes avoids unequal weighing and increases the efficiency of detecting small effects.

Lower bounds for eigenvalues of Schrödinger's equation, N. W. Bazley and D. W. Fox, Phys. Rev. 124, No. 2, 483-492 (Oct. 1961).

This paper gives new results that are useful in estimation of eigenvalues of Schrödinger's equation. Numerical applications are made for the helium atom, an anharmonic oscillator, and a radial Schrödinger equation.

Non-additivity in two-way analysis of variance, J. Mandel, J. A m. Stat. Assoc. 56, 878-888 (Dec. 1961).

In two-way classification analysis of variance situations there often exists a systematic type of row column interaction. A model is proposed in which the interaction is of the type $Q_{i} \gamma_{j}$ where $Q_{i}$ is a parameter of the $i$ th row, not necessarily associated with the main effect for rows, and $\gamma_{i}$ is the main effect for column $j$. The analysis of data according to this model is given, including estimation and tests of significance. The model is more general than that involved in Tukey's "one degree of freedom for non-additivity." The relationship between the two methods is discussed. The application of the method to different types of problems is also discussed.

Advances in orthonormalizing computation, P. J. David and P. Rabinowitz, Advances in Computers II, 55-133 (1961).

This paper contains: (1) a survey of least square approximation techniques in numerical analysis, (2) some recent numerical results on the solution of boundary value problems via the method of orthogonalized particular solutions.

Memory effects in irreversible thermodynamics, R. Zwanzig, Phys. Rev. 124, No. 4, 983-992 (Nov. 15, 1961).

A new generalization of Onsager's theory of irreversible processes is presented. The main purpose is to allow for memory effects or causal time behavior, so that the response to a thermodynamic force comes later than the application of the force. This is accomplished by a statistical mechanical derivation of an exact non-Markoffian kinetic equation for the probability distribution in the space of macroscopic state variables. The memory effect in the resulting transport equations is represented by a time convolution of the thermodynamic forces with memory functions. The latter are timecorrelation functions in the rates of change of the phase functions corresponding to macroscopic quantities. The resulting transport equations are not restricted to small deviations from thermal equilibrium. Onsager's theory is shown to be the low-frequency limit of our causal theory.

Formulae for an accurate intermediary orbit of an artificial satellite, J. P. Vinti, Astronomical .J. 66, No. 9, 514-516 (Nov. 1961).

Formulae are given for computing the drag-free orbit of an artificial satellite of an oblate planet moving in the field of a certain gravitational potential. This potential, expressed in oblate spheroidal coordinates and leading to separability of the Hamilton-Jacobi equation, fits the zeroth and second zonal harmonics exactly and, in the case of the earth, yields more than half of the fourth zonal harmonic. The solution gives periodic terms through the second order in the oblateness parameter and secular terms exactly, for the given potential. It thus furnishes an intermediary orbit which should always remain very accurate.

A comment on Ryser's "normal and integral implies incidence" theorem, K. Goldberg, Am. Math. Monthly 68, No. 8, 7\%0-771 (Oct. 1961).

One of H. J. Ryser's well-known results on matrices satisfying the incidence equation states that if such a matrix is normal and integral it is a 0,1 matrix. The purpose of this note is to show that "integral" can be replaced by "each of its non-zero elements is at least 1 in absolute value," and that the essence of the condition is thus size and not algebraic type.

\section{Other NBS Publications}

\section{Journal of Research 66A (Phys. and Chem.) No. 2 (Mar.- Apr. 1962) 70 cents}

Correction factors for the calibration of encapsulated radium sources. R. M. Lee and T. P. Loftus.

Description and analysis of the second spectrum of tantalum, Ta II. C. C. Kiess.

Vibration-rotation bands of carbonyl sulfide. A. G. Maki, E. K. Plyler, and E. D. Tidwell.

Ionization in the plasma of a copper are. C. H. Corliss.

The vapor pressure of palladium. R. F. Hampson and R. F. Walker.

Revised standard values for $p H$ measurements from 0 to 95 ${ }^{\circ}$ C. R. G. Bates.

Conductometric determination of sulfhydryl groups in swollen polycaprolactam fibers having disulfide and alkylene sulfide crosslinks. S. D. Bruck and S. M. Bailey.

Chromatographic analysis of petroleum fractions used in oilextended rubber. D. J. Termini and A. R. Glasgow.

Cross-sectional correction for computing Young's modulus from longitudinal resonance vibrations of square and cylindrical rods. W. E. Tefft and S. Spinner.

\section{Journal of Research 66C (Engr. and Instr.) No. 2 (Apr.- June 1962) 75 cents.}

Effect of vibration and shock on unsaturated standard cells. R. J. Brodd and W. G. Eicke, Jr.

Experiments on the burning of cross piles of wood. D. Gross. Transfer of NBS X-ray beam calibrations. J. S. Pruitt, A. Allisy, G. Joyet, W. Pohilit, M. Tubiana, and C. Zupančič.

Identification of metallurgical reactions and their effect on the mechanical properties of $17-7 \mathrm{PH}$ stainless steel. H. C. Burnett, R. H. Duff, and H. C. Vacher.

The ideal Lovibond color system. D. B. Judd, G. J. Chamberlin, and G. W. Haupt.

Systems of electrical units. F. B. Silsbee. (See above abstract.)

\section{Journal of Research 66D (Radio Prop.) No. 2 (Mar.-Apr.} 1962) 70 cents.

Atmospheric phenomena, energetic electrons, and the geomagnetic field. J. R. Winckler.

The summer intensity variations of [OI] $6300 \mathrm{~A}$ in the tropics. D. Barbier, F. E. Roach, and W. R. Steiger.

Generation of radio noise in the vicinity of the earth. P. A. Sturrock.

Fading characteristics observed on a high-frequency auroral radio path. J. W. Koch and H. E. Petrie.

Some problems connected with Rayleigh distributions. M. M. Siddiqui. (See above abstract.)

Impedance of a monopole antenna with a radial-wire ground system on an imperfectly conducting half space, part I. S. W. Maley and R. J. King. (See above abstract.)

Theory of the infinite cylindrical antenna including the feedpoint singularity in antenna current. R. H. Duncan. (See above abstract.) 
The $E$-field and $H$-field losses around antennas with a radial ground wire system. T. Larsen.

The electric field at the ground plane near a disk-loaded monopole. J. Hansen and T. Larsen. (See above abstract.)

Journal of Research 66D (Radio Prop.) No. 3 (May-June 1962) 70 cents.

A theory of radar reflections from a rough moon. D. F. Winter.

Alunar theory reasserted. K. M. Siegel and T. B. A. Senior.

Statistical distribution of the amplitude and phase of a multiply scattered field. P. Beckmann.

Amplitude distribution for radio signals reflected by meteor trails, II. A. D. Wheelon.

High resolution pulse measurements of meteor-burst propagation at $41 \mathrm{Mc} / \mathrm{s}$ over a $1,295-\mathrm{km}$ path. R. J. Carpenter and G. R. Ochs.

Ionospheric irregularities and long-distance radio propagation. H. A. Whale.

On the role of the process of reflection in radio wave propagation. F. du Castel, P. Misme, A. Spizzichino, and J. Voge.

Correlation between hourly median scattered signals and simple refractivity parameters. A. S. Dennis.

Observations of radio wave phase characteristics on a highfrequency auroral path. J. W. Koch and W. M. Beery.

Diurnal and seasonal changes in structure of the mid-latitude quiet ionosphere. J. W. Wright.

Schumann resonances of the earth-ionosphere cavityextremely low frequency reception at Kingston, R. I. C. Polk and F. Fitchen.

Propagation of plane electromagnetic waves past a shoreline. J. Bazer and S. N. Karp. (See above abstract)

Currents induced on the surface of a conducting circular cylinder by a slot. G. Hasserjian and A. Ishimaru. (See above abstract)

An experimental study of phase variations in line-of-sight microwave transmissions, K. A. Norton, J. W. Herbstreit, H. B. Janes, K. O. Hornberg, C. F. Peterson, A. F. Barghausen, W. E. Johnson, P. I. Wells, M. C. Thompson, Jr., M. J. Vetter, and A. W. Kirkpatrick, NBS Mono. 33 (Nov. 1, 1961) 55 cents.

Tables of chemical kinetics. Homogeneous reactions (Supplementary tables), NBS Mono. 34 (Sept. 15, 1961) $\$ 2.75$.

Bibliography and index on vacuum and low pressure measurement, W. G. Brombacher, NBS Mono. 35 (Nov. 10, 1961) 60 cents.

Effect of mortar properties on strength of masonry, C. C. Fishburn, NBS Mono. 36 (Nov. 20, 1961) 30 cents.

Tabulation of data on microwave tubes, C. P. Marsden, W. J. Keery, and J. K. Moffitt, NBS Handb. 70, (Nov. 1, 1961) $\$ 1.00$

Research highlights of the National Bureau of Standards, Annual Report, fiscal year 1961. NBS Misc. Publ. 242 (Dec. 1961) 75 cents.

Report of the 46th National Conference on Weights and Measures, 1961. NBS Misc. Publ. 239 (Jan. 1962) 65 cents.

Quarterly radio noise data, June, July, August 1961, W. Q. Crichlow, R. T. Disney, and M. A. Jenkins, NBS Tech. Note 18-11 (PB151377-11) (1961) \$1.50.

Mean electron density variations of the quiet ionosphere, No. 6 -August 1959 , J. W. Wright, L. R. Wescott, and D. J. Brown, NBS Tech. Note 40-6 (PB151399-6) (1961) $\$ 1.50$.

Techniques for computing refraction of radio waves in the troposphere, E. J. Dutton and G. D. Thayer, NBS Tech. Note 97 (PB161598) (1961) $\$ 1.50$.

Performance predictions for single tropospheric communication links and for several links in tandem, A. P. Barsis, K. A. Norton, P. L. Rice, and P. H. Elder, NBS Tech. Note 102 (PB161603) (1961) \$3.00.

Astrophysical and plasma physics research at the National Bureau of Standards, Highlights for 1961, L. M. Branscomb, K. E. Shuler, J. A. Suddeth, NBS Tech. Note 116 (PB161617) (1961) \$1.00.

Variations in frequency of occurrence of sporadic E 19491959, W. B. Chadwick, NBS Tech. Note 117 (PB161618) (1961) 75 cents.
A note on the propagation of certain LF pulses utilized in a radio navigation system, J. R. Johler, NBS Tech. Note 118 (PB161619) (1961) 75 cents.

Computer simulation of street traffic, M. C. Stark, NBS Tech. Note 119 (PB161620) (1961) \$2.25.

Precision calibration of $\mathrm{RF}$ vacuum tube voltmeters, L. F Behrent, NBS Tech. Note 121 (PB161622) (1961) 50 cents.

Papers from the symposium on collision phenomena in astrophysics, geophysics, and masers, M. J. Seaton, M. J. Dalgarno, and C. Pecker, NBS Tech. Note 124 'PB161625) (1961) $\$ 1.00$.

Some relationships between short-wave fadeouts, magnetic crochets, and solar flares, L. W. Acton, J. Geophys. Research 66, 3060-3063 (Sept. 1961).

A simple calibration technique for vibrating sample and coil magnetometers, N. V. Frederick, Proc. IRE 49, 1449 (Sept. 1961)

First pulsed radio soundings of the topside of the ionosphere, R. W. Knecht, T. E. Van Zandt, and S. Russell, J. Geophys. Research 66, 3078-3081 (Sept. 1961).

The half-life of carbon-14, W. B. Mann, W. F. Marlow, and E. E. Hughes, Intern. J. Appl. Radiation and Isotopes 11, No. 2, 57-67 (1961).

Performance characteristics of turbine flowmeters, M. R. Shafer, Trans. ASME J. Basic Eng. Paper No. 61-W A-25 (1961)

Rate of the reaction $\mathrm{NO}+\mathrm{N}, \mathrm{J}$. T. Herron, J. Chem. Phys. 35, No. 3, 1138-1139 (Sept. 1961).

The synthesis of food, A. T. McPherson, Ind. Research, pp. 20-27 (Nov. 1961).

Effect of mercury-alloy ratio on the physical properties of amalgams, W. T. Sweeney and C. L. Burns, J. Am. Dental Assoc. 63, No. 9, 374-381 (Sept. 1961).

Measurement characteristics of farm milk tanks, M. W. Jensen, Scale J., pp. 4-5 (Oct. 1961).

Experimental design and the ASTM committees, W. J. Youden, Materials Research and Standards, 862-867 (Nov. 1961).

Present status of panoramic roentgenography, J. W. Kumpula, J. Am. Dental Assoc. 63, No. 8, 194-200 (Aug. 1961)

Perturbations and rotational intensities observed in CN bands emitted by reactions of organic molecules with nitrogen atoms, N.H. Kiess and H. P. Broida, J. Mol. Spect. 7, No. 3, 194-208 (Sept. 1961).

Sun-time replaced by atomic clocks, R. S. Tipson, Capital Chemist 11, 255 (Nov. 1961).

Transition probabilities in multilevel system: calculation from impulsive and steady-state experiments, T. Carrington, J. Chem. Phys. 35, No. 3, 807-816 (Sept. 1961).

The permanent function as an inner product, M. Marcus and M. Newman, Bull. Am. Math. Soc. 67, No. 2, 223-224 (March 1961).

Thermal conductivity of some commercial iron-nickel alloys, T. W. Watson and H. E. Robinson, Trans. ASME, Series C, J. Heat Transfer 83, No. 4, 403-408 (Nov. 1961).

Exploratory research on demineralization, A. Rose, R. F. Sweeny, T. B. Hoover, V. N. Schrodt, Ch. in Book, Saline Water Conversion, Advances in Chemistry Series No. 27, 50-55 (American Chemical Society, Washington, D.C. 1960).

Molecular structure of propylene, D. R. Lide and D. Christensen, J. Chem. Phys. 35, No. 4, 1374-78 (Oct. 1961).

Measurement of the transition probability of the OI multiplet at 6157 A, W. L. Wiese and J. B. Shumaker, Jr., J. Opt. Soc. Am. 51, No. 9, 937-942 (Sept. 1961).

Deposition of metals from the vapor phase and similarity of the process to electrodeposition, A. Brenner, Trans. Inst. Metal Finishing 38, No. 4, 123-130 (Aug. 1961).

Photographic response to successive exposures of different types of radiation, M. Ehrlich and W. L. McLaughlin, J. Opt. Soc. Am. 51, No. 11, 1172-1181 (Nov. 1961).

On the possibility of rejecting certain modes in VLF propagation, J. R. Wait, Proc. IRE, Letter 49, 1429-1430 (Sept. 1961).

Intramolecular rearrangements. II. Photolysis and radiolysis of 4-methyl-2-hexanone, P. J. Ausloos, J. Phys. Chem. 65, 1616-1618 (1961)

Low-angle X-ray diffraction of crystalline nonoriented poly- 
ethylene and its relation to crystallization mechanisms, L. Mandelkern, A. S. Posner, A. F. Diorio, and D. E. Roberts, J. Appl. Phys. 32, No. 8, 1509-1517 (Aug. 1961). The relaxation times of some paramagnetic dispersions, P. H. Fang, Physica 2\%, 68 (1961).

Infrared spectra of carbon monoxide as a solid and in solid matrices, A. G. Maki, J. Chem. Phys. 35, No. 3, 931-935 (Sept. 1961).

Multiple biologic recording for digital analysis, H. L. Mason, Proc. Interdisciplinary Clinic on the Instrumentation Requirements for Psychophysiological Research, FIER Clinic on Psychophysiological Instrumentation, Lafayette Clinic, p. 65-67 (May 16-17, 1961).

Preparation, transfer, and dilution of a $50 \%$ sodium hydroxide solution, R. G. Bates, Chem.-Anal. 50, No. 4, 117-118 (Dec. 1961).

A waveguide interpretation of 'temperate-latitude spread F' on equatorial ionograms, M. L. V. Pitteway and R. Cohen, J. Geophys. Research 66, 3141-3156 (Oct. 1961).

Relative intensities for the arc spectra of seventy elements, W. F. Meggers, C. H. Corliss, and B. F. Scribner, Spectrochim. Acta 17, No. 11, 1137-1172 (Nov. 1961).

Ground-conductivity determinations at low radio-frequencies by an analysis of the sferic signatures of thunderstorms, J. R. Johler and C. M. Lilley, J. Geophys. Research 66, 3233-3244 (Oct. 1961).

Tongs used in testing for radioactive contamination, T. G. Hobbs, Health Physics 6, No. 3 \& 4, 224a, 224b, 225 (Oct. 1961).

Calibration of vibration pickups at large amplitudes, E. Jones, S. Edelman, and K. S. Sizemore, J. Acoust. Soc. Am. 33, No. 11, 1462-1466 (Nov. 1961).

For a unified grain-size standard, L. L. Wyman and P. E. Penrod, Materials Research \& Standards (ASTM Bull.) 1, No. 8, 638 (Aug. 1961).

Sound absorption by areas of finite sizes, R. K. Cook, Proc. $3 \mathrm{~d}$ Intern. Congress on Acoustics (Elsevier Publishing Co., Amsterdam, 1961).

Infrared spectrum of acetylene, T. A. Wiggins, E. K. Plyler, and E. D. Tidwell, Opt. Soc. Am. 51, No. 11, 1219-1225 (Nov. 1961).

A status report on Algol-60, J. H. Wegstein, Datamation, p. 24 (1961).

Wind resistance of asphalt shingle roofing, W. C. Cullen, Natl. Acad. Sci.-Natl. Research Council, 33-42 (1961).

The interpretation and synthesis of certain spread- $\mathrm{F}$ configuration appearing on equatorial ionograms, W. Calvert and R. Cohen, J. Geophys. Research 66, 3125-3140 (Oct. 1961).

Kinetic isotope effects in the reaction of methyl radicals with ethane, $-\mathrm{d}_{6}$ and ethane-1, 1, 1- $\mathrm{d}_{3}$, J. R. McNesby, J. Phys. Chem. 64, No. 11, 1671 (Nov. 1960).

Hearing by bone conduction, E. L. R. Corliss, E. L. Smith, and J. O. Magruder, Proc. 3d Intern. Congress on Acoustics, p. 53-55 (Elsevier Publ. Co., Amsterdam, The Netherlands, 1959).

A method for the study of vector velocity distribution of low density molecular beams, L. Marton, S. R. Mielczarek, and D. C. Shubert, Book, Rarefied Gas Dynamies, p. 61-65 (Academic Press, Inc., New York, N.Y., 1961).

Expected influence of a localized change of ionosphere height of VLF propagation, J. R. Wait, J. Geophys. Research 66, 3603 (Oct. 1961).

Rate of vaporization of refractory substances, J. J. Diamond, J. Efimenko, R. F. Hampson, and R. F. Walker, J. H. de Boer, et al. (Editors) Reactivity of Solids Proc. Fourth Intern. Symp. Amsterdam, 1960, 725-34 (1960).

Cryogenics and nuclear physics, R. P. Hudson, Science 134, No. 3492, 1733-1736 (Dec. 1, 1961).

A technique for calculating infrared absorption by a regular band, L. R. Megill and P. M. Jamnick, J. Opt. Soc. Am. 51, 1294-1297 (Nov. 1961).

Evaluation of the special world interval program during the IGY, M. E. Nason, J. Geophys. Research 66, 3597-3598 (Oct. 1961).

Crack progapation and the fracture of concrete, M. F. Kaplan, J. Am. Concrete Inst. 58, No. 5, 591-610 (Nov. 1961).
Magnetic field micropulsations and electron bremsstrahlung, W. H. Campbell, J. Geophys. Research 66, 3599-3600 (Oct. 1961).

The effect of lithium bromide on the structural transition of ribonuclease in solution, L. Mandelkern and D. E. Roberts, J. Am. Chem. Soc. 83, 4292 (1961).

Comments on "Plan for the Self-Qualification of Laboratories," A. T. McPherson, ASTM Materials Research \& Standards 1, No. 9, 729, 730, 733 (Sept. 1961).

Timing potentials of Loran C, R. H. Doherty, G. Hefley, and R. F. Linfield, Proc. IRE 49, 1659-1673 (Nov. 1961).

Pan American standards of mutual benefit to Latin America and the U.S., A. T. McPherson, Foreign Commerce Weekly (International Affairs, Department of Commerce, Washington, D.C.) p. 1 (Nov. 13,1961 )

Polymorphism of $\mathrm{ABO}_{3}$ type rare earth borates, E. M. Levin, R. S. Roth, and J. B. Martin, Am. Mineralogist 46, 1030-1055 (Sept. 1961).

Sun storms and the earth: The aurora polaris and the space around the earth, S. Chapman, Am. Scientist 49, No. 3, 249-284 (Sept. 1961).

Maxwell and modern colorimetry, D. B. Judd, J. Photographic Sci. 9, No. 6, 341-352 (Nov.-Dec. 1961).

Colorimetric determination of 5,6-dichloro-2-benzoxazolinone in leathers, S. Dahl, J. Am. Leather Chemists Assoc. LVII, No. 1 (Jan. 1962).

Formation of polymer crystals with folded chains from dilute solution, J. I. Lauritzen, Jr., and J. D. Hoffman, J. Chem. Phys. 31, No. 6, 1680-1681 (Dec. 1959).

This works for us - approval books for a science library, V. S. Barker, Special Libraries 52, No. 3, 471-472 (Oct. 1961).

Dielectric properties of solid polymers, A. J. Curtis, SPE Trans., 82-85 (Jan. 1962).

Chemical reactions at very low temperatures, A. Thomas, Trans. Faraday Soc. 57, No. 446, Pt. 10, 1679-1685 (Oct. 1961).

Theoretical dielectric behavior of an ethyl sterate-heneicosane mixture, M. G. Broadhurst, J. Chem. Phys. 33, No. 1, 221-226 (July 1960).

A statistical comparison of the wearing characteristics of two types of dollar notes, E. B. Randall, Jr., and J. Mandel, Materials Research and Standards (ASTM Bull.) 2, No. 1, 17-25 (Jan. 1962).

5,6-dichloro-2-benzoxazolinone as a leather fungicide, S. Dahl and A. M. Kaplan, J. Am. Leather Chemists Assoc. LVI, No. 12, (Dec. 1961).

Departure from the Saha equation for ionized helium. II Atmospheric thicknesses too small to satisfy detailed balance in the resonance lines, R. N. Thomas and J. B. Zirker. Astrophys. J. 134, 740-746 (Nov. 1961)

Electron diffraction studies on solid $\alpha$-nitrogen, E. M. Horl and L. Marton, Acta Cryst. 14, No. 11, Pt. 1 (Jan. 1961).

On the impedance of long wire suspended over the ground, J. R. Wait, Proc. IRE 49, No. 10 (Oct. 1961).

Automatic screening of normal and abnormal electrocardiograms by means of a digital electronic computer, $\mathrm{H} . \mathrm{V}$. Pipberger, R. J. Arms, and F. W. Stallmann, Prof. Soc. Experimental Biology and Medicine 106, 130-132 (1961).

Electromagnetic bearing, H. Sixsmith, Rev. Sci. Instr. 32, 1196-1197 (Nov. 1961).

Franck-Condon factors and the shape of ionization efficiency curves, M. E. Wacks and M. Krauss, J. Chem. Phys. 35, No. 5, 1902-1903 (Nov. 1961).

On the average atmospheric radio refractive index structure over North America, B. R. Bean and J. D. Horn, Beitr. Phys. Atmos. 34, 92-104 (1961).

Concerning the bi-exponential nature of the tropospheric radio refractive index, B. R. Bean, Beitr. Phys. Atmos. 34, 81-91 (1961).

Atomic beam frequency standards, R. C. Mockler, Advances in Electronics and Electron Phys. 15, 1-71 (1961).

Traveling pressure waves associated with geomagnetic activity, P. Chrzanowski, G. Greene, K. T. Lemmon, and J. M. Young, J. Geophys. Research 56, No. 11, 3727-3733 (Nov. 1961) 
A study of the fluorescence of cellulosic polymers, K. F. Plitt and S. D. Toner, J. Appl. Polymer Sci. 5, No. 17, 534-538 (1961).

Use of an operational amplifier with Helmholtz coils for reducing ac induced magnetic fields, L. A. Marzetta, Rev. Sei. Instr. 32, No. 11, 1192-1195 (Nov. 1961).

Drift mobility of an ionic impurity in an electric field, J. R. Manning, Phys. Rev. 125, No. 1, 103-108 (Jan. 1962).

Some observations of metal distribution, G. Ogburn and M. A. Morris, Plating Mag. 49, No. 1, 72-75 (Jan. 1962).

Comments on K. Vozoff's paper "Calibration of pulsation detector coils," J. R. Wait, J. Geophys. Research 66, No. 10, 3603 (Oct. 1961).

Dielectric properties of polyamides, A. J. Curtis, J. Chem. Phys. 34, No. 5, 1849-1850 (May 1961).

Precision of reverberation chamber measurements of sound absorption coefficients, R. V. Waterhouse, Book, Proc. 3d Intern. Congress on Acoustics, Stuttgart, Germany
P. 886 (Elsevier Publ. Co. Amsterdam, The Netherlands, 1959).

Concerning radiosondes, lag constants, and radio refractive index profiles, B. R. Bean and E. J. Dutton, J. Geophys. Research 66, 3717-3722 (Nov. 1961).

On the interpretation of prominence spectra IV. The Balmer and Paschen continua in a quiet prominence, J. T. Jefferies and F. Q. Orrall, Astrophys. J. 134, No. 3 (Nov. 1961).

*Publications for which a price is indicated (except for Technical Notes) are available only from the Superintendent of Documents, U.S. Government Printing Office, Washington 25, D.C. (foreign postage, one-fourth additional). Technical Notes are available only from the Office of Technical Services, U.S. Department of Commerce, Washington 25, D.C. (Order by PB number). Reprints from outside journals and the NBS Journal of Research may often be obtained directly from the authors. 